\title{
Expression of Vimentin Intermediate Filament for Vascular Development in Olive Flounder (Paralichthys olivaceus)
}

\author{
Hyun Yang, Jang-Wook Lee, Jae Koo Noh, Hyun Chul Kim, Choul-Ji Park, Jong-Won Park, \\ In Joon Hwang, Sung Yeon Kim and ${ }^{\dagger}$ Jeong-Ho Lee \\ Genetics and Breeding Research Center, NFRDI, Geoje 656-842, Republic of Korea
}

\begin{abstract}
Cardiovascular system is the primary organ to develop and reach a functional state, which underscores the essential role of the vasculature in the developing embryo. The vasculature is a highly specialized organ that functions in a number of key physiological works including the carrying of oxygen and nutrients to tissues. It is closely involved in the formation of heart, and hence it is essential for survival during the hatching period. The expression of genes involved during vascular development in the olive flounder (Paralichthys olivaceus) in the days after hatching is not fully understood. Therefore, we examined the expression patterns of genes activated during the development of flounder. Microscopic observations showed that formation of blood vessels is related to the expression of the vimentin gene. Also, the temporal expression patterns of this vimentin-like gene in the developmental stages and in the normal tissues of olive flounder. The purpose of this study was to examine the expression patterns of vimentin in normal tissues of the olive flounder and during the development of the vascular system in newly hatched olive flounders and HIF-1 plays a vital role in the formation of blood vessels during development. Vimentin expression was strong at the beginning of the development of blood vessels, and was present throughout all developmental stages. Our findings have important implications with respect to the roles of vimentin and HIF-1 in the development and evolution of the first blood vessels in olive flounder. Further studies are required to elucidate the vimentin-mediated hypoxic response signal transduction and to decipher the functional role of vimentin in developmental stages.
\end{abstract}

Key words : Vascular development, Intermediate Filament (IF), Vimentin, Olive flounder.

\section{INTRODUCTION}

Development of the cardiovascular system begins soon after gastrula concomitant with somite formation. In vertebrates, the cardiovascular system is the first functional organ system to arise and is critical in providing adequate oxygen and nutrient delivery to rapidly developing tissues (Chung \& Ferrara, 2007; Patel-Hett \& D'Amore, 2011). Cardiovascular system is very important in the develop- mental stages of the olive flounder life cycle. In most oviparous fish, including the olive flounder (Paralichthys olivaceus), embryo and larval survival depends upon timely vascular formation mediated by specific developmental gene expressions. Hypoxia triggers responses during developmental stage that play roles, cell to cell interaction and inhibit growth and development in fish purview from invertebrates to animals (Kajimura et al., 2006; Dunwoodie, 2009). To make sure survival in a variety of environments,

\footnotetext{
Manuscript received 8 May 2014, Received in revised form 14 May 2014, Accepted 20 May 2014

${ }^{\dagger}$ Corresponding Author : Jeong-Ho Lee, Genetics and Breeding Research Center, NFRDI, Geoje 656-842, Republic of Korea, Tel: +82-55-639-5811, Fax: +82-55-639-5809, E-mail: jhlee7124@korea.kr

This is an Open Access article distributed under the terms of the Creative Commons Attribution Non-Commercial License (http:// creativecommons.org/licenses/by-nc/3.0) which permits unrestricted non-commercial use, distribution, and reproduction in any medium, provided the original work is properly cited.
} 
fish embryos have evolved mechanisms to respond to hypoxia and repair oxygen homeostasis (Freeburg \& Abrahamson, 2003). Because many embryonic tissues develop rapidly, they often outpace their vascular supply. Hypoxia-inducible genes are crucial regulatory proteins for the development of embryo to hypoxia, and they stimulate angiogenesis through activation of the vascular endothelial growth factor (VEGF) gene (Moeller et al., 2004; Liao \&Johnson, 2007). Hypoxic stress response has been shown that rework the structure and mobility of endothelial cells in a way that contributes to a formation of vascular system. These mechanisms play an important role in blood vessel formation and communication with leukocytes as well as in regulation of intermediate filament in hypoxia response. The Intermediate filaments (IF) constitute one of the three major components of the cytoskeleton which also include actin microfilaments and tubulin microtubules (Goldman et al., 2012; Holthofer et al., 1984; Styers et al., 2005). Microtubules and actin filaments are dynamic structures known to play key roles in neuronal development and origin development, such as organization of neuronal cell, migration, axonal outgrowth, and intracellular transport, the functions of IF proteins in neurons have remained, until recently, more elusive (Hyder et al., 2007; Herrmann et al., 1989; Karabinos et al., 2001). The extracellular domains of desmocollin and desmoglein engage with their counterparts of adjacent cells to form the intercellular connection. In addition, in the myoplasm, intermediate filaments connect to dense bodies to which actin filaments also attach (Fuchs \& Cleveland, 1998; Prahlad et al., 1998). These structures act in concert to control cell morphology and biomechanics. Vimentin is a main intermediate filament protein in airway and vascular tubule, whereas latest is expressed in smooth muscle (Qin et al., 2009) and micro arteries (Guo et al., 2005; Nekrasova et al., 2007).

The expression of intermediate filaments in flatfish developmental stages has not been sufficiently studied. In this report, we show that vascular formation causes changes in the development of olive flounder that are accompanied by changes in the expression patterns of HIF-1 and vimentin genes from fertilization to the post-hatching period. Additionally, this study examines the expression patterns of vimentin in several tissues of the olive flounder.

\section{MATERIALS AND METHODS}

\section{Fish and RNA purification}

All experimental fish were raised at Genetics and Breeding Research Center, National Fisheries Research and Development Institute (NFRDI) and maintained in 10 tons flow through tank at $20 \pm 1{ }^{\circ} \mathrm{C}$ under a natural photoperiod. Different stages of Morula, Blastula, Gastrula, Neurula, $(0.92 \pm 0.02 \mathrm{~mm})$ and larvae $(2.49 \pm 0.34 \mathrm{~mm})$ development were described from fish kept at $20^{\circ} \mathrm{C}$ in the tank. Several tissues of 2 years ( $42 \mathrm{~cm} \pm$ SEM) old were used to in olive flounder. The samples of fish were randomly collected and frozen in $70^{\circ} \mathrm{C}$ deep freezer until isolation of total RNA. Several tissues were homogenized for $20 \mathrm{sec}$ with Trizol reagent (Invitrogen, Carlsbad, CA, USA).

\section{Microscopic assay}

Larvae were examined as previously described, fixed at room temperature, in $2.5 \%$ glutaraldehyde (Polysciences, Inc., Warrington, PA) in $0.1 \mathrm{M}$ sodium cacodylate- $\mathrm{HCl}$ buffer, $\mathrm{pH}$ 7.3, for $10 \mathrm{~min}$, and post fixed in $1 \%$ paraformaldehyde (Sigma-Aldrich, CA, USA) in the same buffer, for 20 min with $1 \%$ uranyl acetate for $1 \mathrm{~h}$ and ethanol dehydration. The samples were examined under a stereo microscope (ZEISS CL1500 ECO Jena, Germany) imaging system at $\times 300$ and $\times 500$ magnification of development was determined.

\section{Bioinformatic analysis}

Bioinformatic analysis was conducted to determine gene 
identities using Gene Master software (Ensoltek, Beaverton, USA). ESTs were assembled in clusters of contiguous sequences (conting) using ICA tools program (parsons, 1995). Gene annotation procedures and homology searches of the sequenced ESTs have been locally done by BLASX for amino acid similarity comparisons. Matches with the Expect value (E) less than $1.0 \mathrm{xe}^{-4}$ were considered to be significant; all ESTs were not identified as orthologs of known genes were designated as unknown EST clones.

\section{Reverse transcription-polymerase chain reaction (RT-PCR)}

Total RNA was extracted using the Trizol Reagent (Invitrogen, Carlsbad, CA, USA) according to the manufacturer's protocol. DNase-I (Sigma-Aldrich, CA, USA) was treated for removing genomic DNA contamination from RNA for $30 \mathrm{~min}$ at $37^{\circ} \mathrm{C}$. The RNA samples were extracted with phenol/chloroform to inactivate the DNase I. RNA concentration was measured with spectrophotometer (Gene-Quant, Pharmacia Biotech), quality of RNA was checked by gel electrophoresis ( $1 \%$ agarose gel) and stored at $-80^{\circ} \mathrm{C}$ until further use. RNA (100 ng) from each sample was transcribed to cDNA using Transcriptor First Strand cDNA synthesis kit (Roche Ltd., SWISS). The amplification was performed with AmpliTag Gold DNA Polymerase (Applied Biosystems., CA, USA) and $M y$ cycler Thermal Cycler (Bio-Rad Laboratories Inc., Hercules, CA, USA) using the following parameters: denaturation at $95^{\circ} \mathrm{C}$ for 10 minutes and 32 cycles of reactions of denaturation at $98^{\circ} \mathrm{C}$ for $10 \mathrm{~s}$, annealing at $60^{\circ} \mathrm{C}$ for $30 \mathrm{~s}$, and elongation at $72^{\circ} \mathrm{C}$ for $45 \mathrm{~s}$. An aliquot of each PCR product was subjected to $1.5 \%(\mathrm{w} / \mathrm{v})$ agarose gel electrophoresis and visualized by staining with ethidium bromide. A search of the National Center for Biotechnology Information (NCBI) data base revealed a sequence similar to that of HIF-1, a set of expressed sequence tags (ESTs) of olive flounder, and a derived partial sequence of vimentin. The $5^{\prime}$ forward and $3^{\prime}$ reverse-complement PCR primers for amplification of each gene were as follows: HIF-1 (5'-AGTCCAAATTCATGCGGAAA-3') and (5'GCTTTCAATTCCCTGG GTTT-3'), Vimentin (5'-CCT GCCGAACTTCTCATCTC-3') and (5'-TCCTGGAGAGT

GCATG CTAA-3') $\beta$-Actin (5'-TGATGAAGCCCAGAG CAAGA-3') and (5'-CTCCATGTCATC CCAGTTGG-3'). Relative amount of each messenger RNA was quantified by dividing by density of housekeeping gene (Gene bank, HQ 386788.1).

\section{Real-time-PCR assay}

To evaluate arrestin mRNA levels, these primers were specifically designed to detect and quantify cDNA sequences without detecting genomic DNA. The Fast-Start DNA Master SYBR Green I (Roche Ltd., SWISS) was used as fluorescent reporter dye to detect amplification products in 7500 Fast Real Time PCR System (Applied Biosystems Inc. Carlsbad, CA, USA) using the following cycling conditions: denaturation at $95^{\circ} \mathrm{C}$ for $10 \mathrm{~min}$ and 40 cycles of reactions of denaturation at $95^{\circ} \mathrm{C}$ for $10 \mathrm{~s}$, annealing at $58^{\circ} \mathrm{C}$ for $30 \mathrm{~s}$, and elongation at $72^{\circ} \mathrm{C}$ for $30 \mathrm{~s}$. Each sample was tested in triplicate to ensure statistical significance. The PCR efficiency (E\%) of gene was derived from perforin (96.2\%) and $\beta$-Actin (95.4\%) respectively. The relative quantification of arrestin gene expression was performed using the comparative $C_{\mathrm{t}}$ method. The $C_{\mathrm{t}}$ value is defined as the point where a statistically significant increase in the fluorescence has occurred. The number of PCR cycles $\left(C_{\mathrm{t}}\right)$ required for the ROX intensities to exceed a threshold just above background was calculated for the test and reference reactions. In all experiments, $\beta$-Actin was used as the endogenous control. Results were analyzed in a relative quantitation study with the vehicle treated.

\section{Statistical analysis}

Data were analyzed using Sigma plot for Windows (Jandel Scientific, San Rafael, CA, USA). For unpaired matched comparative analysis of multiple groups, an analysis 
of variance (ANOVA) was performed. Data that did not meet normality assumptions were subjected to one way ANOVA on ranks, and then pair wise comparisons were made using the Student-Newman-Keuls (SNK) method.

\section{RESULTS}

1. Early development of blood vessels in olive flounder (Paralichthys olivaceus)

To determine the origins of the vascular system of the olive flounder during the early stages of development, we used a dissecting stereo microscope to observe the lateral side of live olive flounder larvae 1 day after hatching (DAH). The most striking observation in the flounder larvae was that the beating heart was visible at $1 \mathrm{DAH}$, while the formation of blood vessels was in the developmental stage. During this period, the heart, lymph nodes, and the blood vessels all developed to their normal size and shape (Fig. 1A, B). The initial morphological changes that lead to the formation of blood vessels in olive flounder larvae were clearly visible as early as 1 DAH. The vascular system of 1-DAH larvae consists of a dorsal aorta, cardinal vein, and intersegmental vessels (Fig. 1B). At $1 \mathrm{DAH}$, the intersegmental vessels surround the notochord and the posterior cardinal vein extends laterally to connect with the dorsal aorta, which functions as the collecting system; this is illustrated in Fig. 1B. These findings demonstrate that the development of normal physiology in flounder larvae can be at least partially attributed to the development of the blood vessels.

\section{The identification of the genes encoding vimentin} from the olive flounder using expressed sequence tags

In a previous study, we constructed a cDNA library using samples from the eyes of olive flounder; 270 clones were screened against this library (Lee et al., 2009; Lee et al., 2010). Utilizing the cDNA library, several expressed sequence tags (ESTs) were found to be homologous to
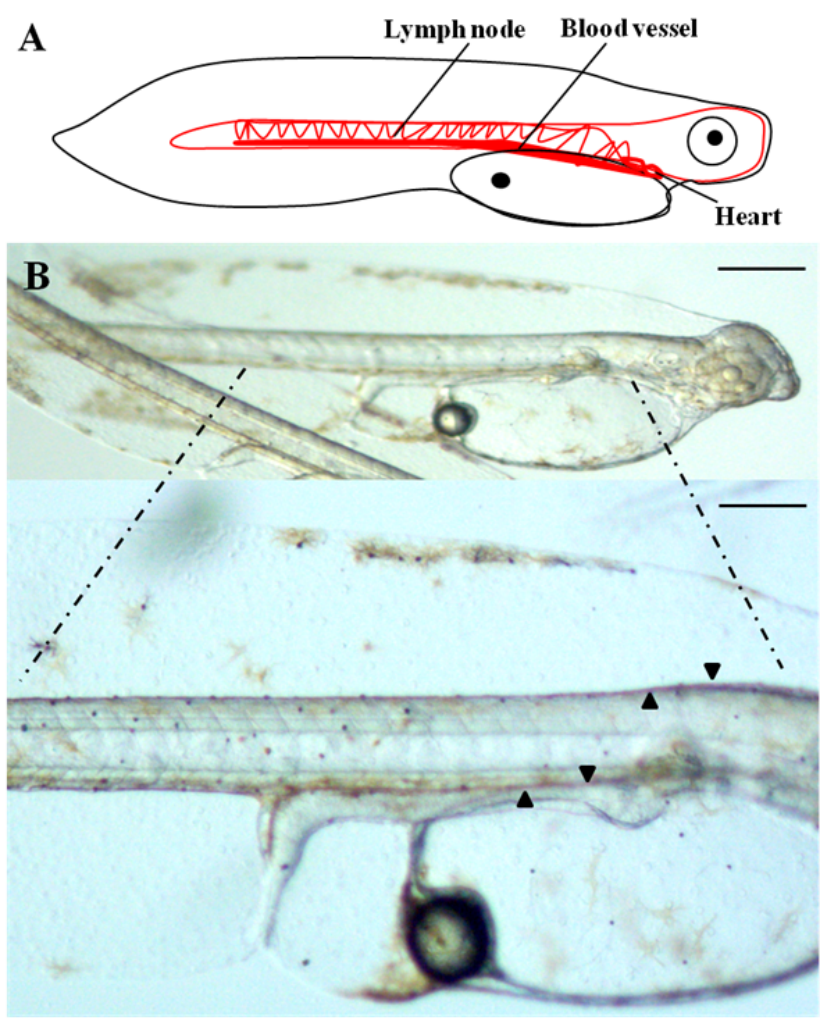

Fig. 1. Development of blood vessel formation of the olive flounder (Paralichythys olivaceus). The experiment was fertilized eggs of olive flounder from the tank, oxygen supply and maintains a temperature of $20^{\circ} \mathrm{C}$. (A) Schematic lateral view of the blood vessel and lymph node of a flat fish with key features labeled. (B) Photograph was shown during after hatching for 1 day, Magnification: $\times 300, \times 500$. The following structures can be identified in deve-lopment olive flounder larvae under dissecting stereomicroscopes. Black arrows showed that blood vascular formation to larva stage in olive floubder. Scale bar, $300 \mu \mathrm{m}$.

genes that are related to the formation of the olive flounder's ocular structures; in addition, one EST demonstrated significant sequence similarity with the genes responsible for the expression of vimentin, a protein that plays an important role in the ocular system. A blast search of the GenBank database was performed on the homologs of the olive flounder-derived vimentin. The alignment analysis demonstrated that the amino acid sequence of 
A

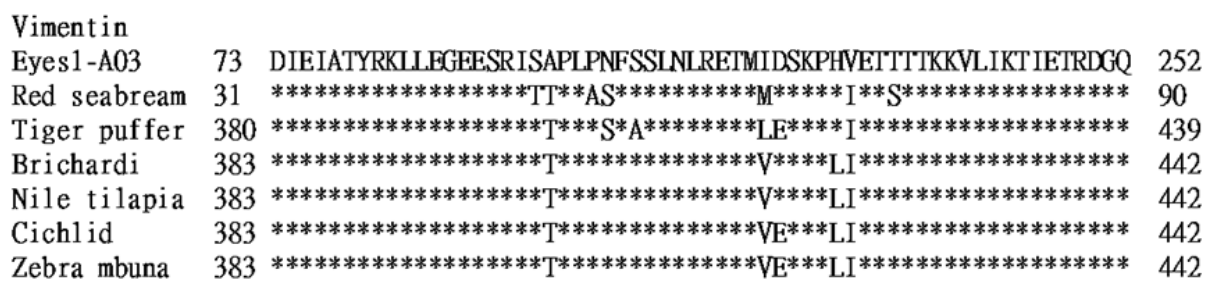

$\begin{array}{llllc} & & & & \text { Ident ity } \\ \text { Eyes1-A03 } & 253 & \text { VINESTONHDDME } & 291 & (100 \%) \\ \text { Red seabream } & 91 & * * * * * * * * * * * * * & 103 & (90 \%) \\ \text { Tiger puffer } & 440 & * * * * * * * * * * * * * & 452 & (92 \%) \\ \text { Brichardi } & 443 & * * * * * * * * * * * * D & 455 & (93 \%) \\ \text { Nile tilapia } & 443 & * * * * * * * * * * * * D & 455 & (93 \%) \\ \text { Cichlid } & 443 & * * * * * * * * * * * * D & 455 & (92 \%) \\ \text { Zebra mbuna } & 443 & * * * * * * * * * * * * D & 455 & (92 \%)\end{array}$

Fig. 2. The vimentin gene was deduced by amino acid alignment assay for the flounder. (A) The amino acid sequence alignment was deduced for the olive flounder vimentin gene. Vimentin sequences are aligned with the several spices. GenBank accession numbers of each species are as follows: Red seabream (Pagrus major) AAP20222.1, Tiger puffer (Takifugu rubripes) XP_003975498.1, Brichardi (Neolamprologus brichardi) XP_006792231.1, Nile tilapia (Oreochromis niloticus) XP_003438114.1, Cichlid (Pundamilia nyererei) XP_0057425 71.1, Zebra Mbuna (Maylandia zebra) XP_004542987.1. Clone Eyes1-A03 is indicated by Asterisk $(*)$. It is indicates the invariant and conserved residues in Arrestin. The percentages in parentheses indicate the overall amino acid identities.

olive flounder-derived vimentin is homologous to the sequences of genes that encode vimentin from other organisms, demonstrating 93-90\% identity. In addition, the vimentin of the olive flounder shared the greatest level of similarity with the red seabream, tiger puffer, brichardi, Nile tilapia, cichlid, and zebra mbuna (Fig. 2A).

\section{Analysis of the expression of vimentin genes in} response to hypoxic stress

The expression of the newly identified genes encoding HIF-1 and vimentin in olive flounder embryos and larvae was detected using traditional reverse transcription-polymerase chain reaction (RT-PCR). Although the expression of the genes encoding HIF-1 was detectable post-fertilization, the expression level was found to be the greatest at 14 hour post fertilization (HPF), and decreased quickly to until 28 HPF. The expression of the genes encoding vimentin was also detectable post-fertilization, and the expression of the genes could be detected $24 \mathrm{HPF}$, with the level of expression increasing continuously up to $5 \mathrm{DAH}$ (Fig. 3A). The expression of HIF-1 and vimentin in the olive flounder was examined at various stages of development by using Real-time-PCR. The expression of HIF-1 and vimentin was found similar from post-fertilization or $24 \mathrm{HPF}$ to 5 DAH (Fig. 3B, C). When examining the expression patterns in the tissues of the olive flounder, vimentin mRNA was found to be expressed at similar levels in the brain, fin, eye, and spleen, while it was not expressed in the muscles, liver, kidney, and gills (Fig. 4A). The expression of vimentin was found to increase with age in tissues containing neuronal intermediate filaments (IFs), but it decreased with age in non-IF tissues (Fig. 4A, B). These results show that vimentin is expressed during the formation of the vascular system, suggesting that HIF-1 
A
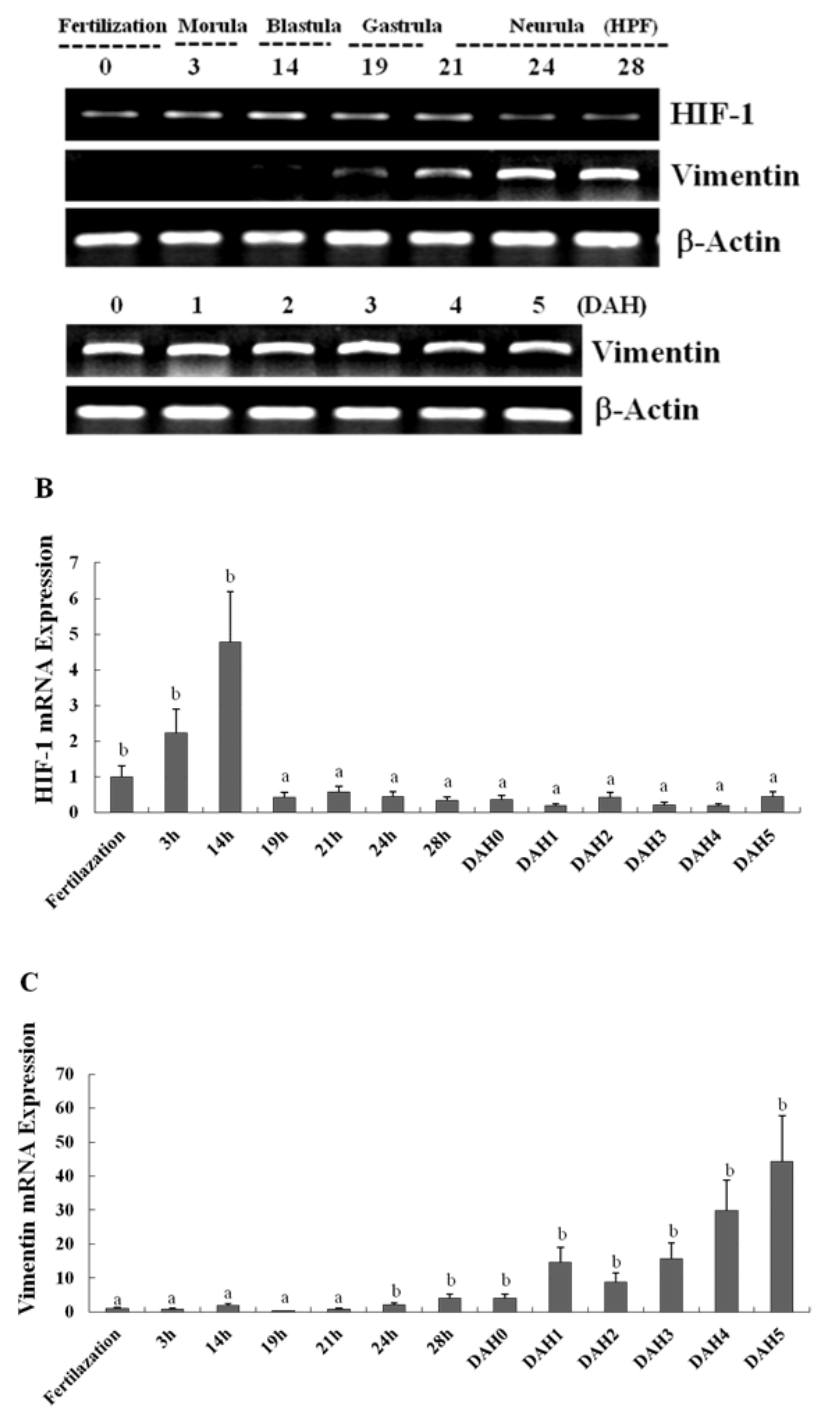

Fig. 3. Expression of HIF-1 and vimentin gene induces in the early development. (A) The experiment was flounder fertilized eggs from the tank, oxygen supply and maintain a temperature of $20^{\circ} \mathrm{C}$. Embryo and larva were harvested during hours post fertilization (HPF) and days after hatching (DAH) for the indicated periods. The RNA extracted and vimentin was analyzed by RT-PCR method. (B, C) The mRNA expression of perforin was analyzed by real-time PCR. Different letters over each bar with the standard deviation represent significant differrences one group according to unpaired matched comparisons $(p<0.05)$.
A

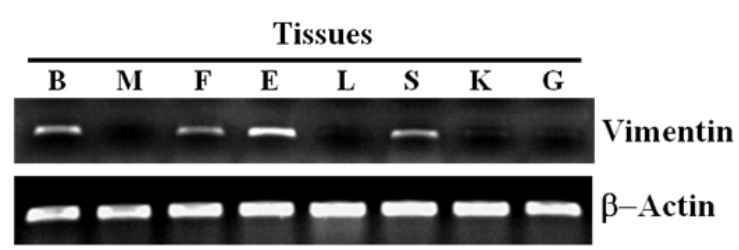

B

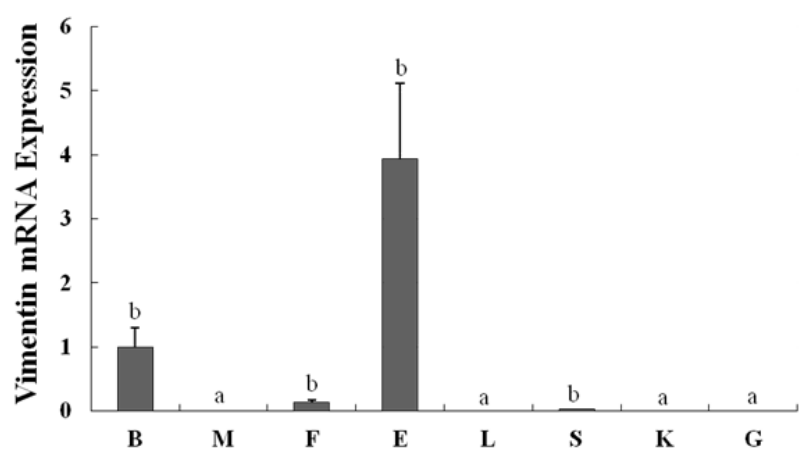

Fig. 4. Expression of vimentin gene induces from several tissues in the olive flounder. Experiments are examined with various periods of adult fish. (A) Vimentin gene expression from the segmental tissue (B: brain, M: muscle, F: fin, E: eye, L: liver, $\mathrm{S}$ : spleen, K: kidney, G: gill) for the olive flounder by using RT-PCR analysis. (B) The mRNA expression of vimentin was analyzed by real-time PCR. Different letters over each bar with the standard deviation represent significant differences one group according to unpaired matched comparisons $(p<$ $0.05)$.

plays a role in the formation of blood vessels during the early stages of development.

\section{DISCUSSIONS}

The changes that were observed in the expression of several development-mediating genes can be at least partially attributed to the formation of blood vessels during the early developmental stages in olive flounder larvae. At $1 \mathrm{DAH}$, it was possible to visualize the vascular system lateral to the notochord (Fig. 1B). Our results suggest that normal development of the vasculature is essential for 
ongoing angiogenesis. However, the formation of blood vessels in olive flounder larvae during the developmental stages has not yet been described in any study. The modulation of gene expression by cellular responses to hypoxic stress plays an essential role in early development. For example, a previous study has demonstrated that knocking down HIF- $1 \alpha$, HIF- $2 \alpha$ and HIF-1 $\beta$ in mice (Kotch et al., 1999; Tomita et al., 2003), results in abnormal-bloodvessel development and death. In addition, knockout of HIF-1 $\alpha$ resulted in mesenchymal cell death leading to death occurring during the middle period of gestation; this occurred owing to severe defects in cardiovascular and neuronal plate development (Grimm et al., 2002; Semenza \& Prabhakar, 2007). Although HIF-1 $\alpha$ is essential for VEGF induction during embryonic development, it is not solely responsible for VEGF activation (Okada et al., 2005). Mutations to HIF- $1 \alpha$ do prevent endothelial cells from reaching full maturity (Manalo et al., 2005). Consistent with previous reports, we found that, in the olive flounder, HIF-1 is expressed during the early stages of development, and that vimentin is expressed during the formation of blood vessels and in the neuronal organs, lymphoid tissue, and connective tissue (Fig. 3, Fig. 4). Various studies have previously reported an increase in the development of endothelial mono layers in cell cultures in response to conditions of hypoxic stress. The key proteins of intermediate filament proteins in endothelial cells are vimentin and keratin (Tsuruta \& Jones, 2003). Most blood vessels and neuronal tubes in endothelial cells are known to consist of vimentin. It has been reported that astrocytes from vimentin-knockout mice lack properly developing blood vessels and growing nerve fibers (Gariano et al., 1996). Recent studies examining the lymphocytes from vimentin-knockout models indicate that vimentin is essential for the feedback mechanisms of leukocytes and that its absence compromises the leukocyte barrier (Nieminen et al., 2006; Leong et al., 2008). RT-PCR data have demonstrated that vimentin mRNA is expressed and is detectable until 5 DAH (Fig. 3A, C). An interesting characteristic of the expression of vimentin in intermediate-filaments is the relatively high expression during blood-vessel formation and in lymphoid organs. Blood-vessel formation was observed during the early stages of developmental, and the genes encoding vimentin were highly expressed at these stages. This suggests that vimentin may play a crucial role in the development of the vascular system during the embryonic and larval stages in the olive flounder life cycle. Consequently, it is possible to conclude that vimentin is an important cytoskeleton protein and that it is a key constituent of connective tissue. Additionally, vimentin is important in the growth and maturation of the organs of the circulatory system, and plays an important role during periods of hypoxic stress.

To summarize, this analysis of the expression of vimentin during the developmental stages of the olive flounder might provide information that could be useful in understanding initial blood vessel formation and maturation. Further functional studies on this gene will help to elucidate the molecular regulatory mechanisms and the signal-transduction systems involved in the formation of the vascular system in olive flounder, as well as identifying the genes responsible for modulating the activity of vimentin.

\section{ACKNOWLEDGEMENTS}

This work was supported by a grant from the National Fisheries Research and Development Institute (NFRDI), contribution number RP-2014-BT-15.

\section{REFERENCES}

Chung AS, Ferrara N (2007) Developmental and pathological angiogenesis. Annu Rev Cell Dev Biol 27:563-584.

Dunwoodie SL (2009) The role of hypoxia in development 
of the mammalian embryo. Dev Cell 17:755-773.

Freeburg PB, Abrahamson DR (2003) Hypoxia-inducible factors and kidney vascular development. J Am Soc Nephrol 14:2723-2730.

Fuchs E, Cleveland DW (1998) A structural scaffolding of intermediate filaments in health and disease. Science 279:514-519.

Gariano RF, Sage EH, Kaplan HJ, Hendrickson AE (1996) Development of astrocytes and their relation to blood vessels in fetal monkey retina. Invest Ophthalmol Vis Sci 37:2367-2375.

Goldman RD, Cleland MM, Murthy SN, Mahammad S, Kuczmarski ER (2012) Inroads into the structure and function of intermediate filament networks. J Struct Biol 177:14-23.

Grimm C, Wenzel A, Groszer M, Mayser H, Seeliger M, Samardzija M, Bauer C, Gassmann M, Reme CE (2002) HIF-1-induced erythropoietin in the hypoxic retina protects against light-induced retinal degeneration. Nat Med 8:718-724.

Guo M, Ehrlicher AJ, Mahammad S, Fabich H, Jensen MH, Moore JR, Fredberg JJ, Goldman RD, Weitz DA (2013) The role of vimentin intermediate filaments in cortical and cytoplasmic mechanics. Biophys J 105: 1562-1568.

Herrmann H, Fouquet B, Franke WW (1989) Expression of intermediate filament proteins during development of Xenopus laevis. I. cDNA clones encoding different forms of vimentin. Development 105:279-298.

Holthofer H, Miettinen A, Lehto VP, Lehtonen E, Virtanen I (1984) Expression of vimentin and cytokeratin types of intermediate filament proteins in developing and adult human kidneys. Lab Invest 50:552-559.

Hyder CL, Isoniemi KO, Torvaldson ES, Eriksson JE (2007) Insights into intermediate filament regulation from development to ageing. J Cell Sci 124:1363-1372. Kajimura S, Aida K, Duan C (2006). Understanding hypoxia- induced gene expression in early development: in vitro and in vivo analysis of hypoxia-inducible factor 1regulated zebra fish insulin-like growth factor binding protein 1 gene expression. Mol Cell Biol 26:1142-1155.

Karabinos A, Schmidt H, Harborth J, Schnabel R, Weber K (2001) Essential roles for four cytoplasmic intermediate filament proteins in Caenorhabditis elegans development. Proc Natl Acad Sci USA 98:7863-7868.

Kotch LE, Iyer NV, Laughner E, Semenza GL (1999) Defective vascularization of HIF-1alpha-null embryos is not associated with VEGF deficiency but with mesenchymal cell death. Dev Biol 209:254-267.

Lee JH, Noh JK, Kim HC, Park CJ, Min BH, Kim YO (2009) EST-based identification of genes expressed in the brain of the olive flounder Paralichthys olivaceus Fish Aqua Sci 12(4):286-292.

Lee JH, Noh JK, Kim HC, Park CJ, Min BH, Ha SJ (2010) Molecular characterization of the ocular EST clones from olive flounder, Paralichthys olivaceus Dev Reprod 14(2):107-113.

Leong HS, Mahesh BM, Day JR, Smith JD, McCormack AD, Ghimire G, Podor TJ, Rose ML (2008) Vimentin autoantibodies induce platelet activation and formation of platelet-leukocyte conjugates via platelet-activating factor. J Leukoc Biol 83:263-271.

Liao D, Johnson RS (2007). Hypoxia: a key regulator of angiogenesis in cancer. Cancer Metastasis Rev 26: 281-290.

Manalo DJ, Rowan A, Lavoie T, Natarajan L, Kelly BD, Ye SQ, Garcia JG, Semenza GL (2005). Transcriptional regulation of vascular endothelial cell responses to hypoxia by HIF-1. Blood 105: 659-669.

Moeller BJ, Cao Y, Vujaskovic Z, Li CY, Haroon ZA, Dewhirst MW (2004). The relationship between hypoxia and angiogenesis. Semin Radiat Oncol 14:215-221.

Nekrasova OE, Mendez MG, Chernoivanenko IS, TyurinKuzmin PA, Kuczmarski ER, Gelfand VI, Goldman 
RD, Minin AA (2011) Vimentin intermediate filaments modulate the motility of mitochondria. Mol Biol Cell 22:2282-2289.

Nieminen M, Henttinen T, Merinen M, Marttila-Ichihara F, Eriksson JE, Jalkanen S (2006) Vimentin function in lymphocyte adhesion and transcellular migration. Nat Cell Biol 8:156-162.

Okada K, Osaki M, Araki K, Ishiguro K, Ito H, Ohgi S (2005) Expression of hypoxia-inducible factor (HIF1alpha), VEGF-C and VEGF-D in non-invasive and invasive breast ductal carcinomas. Anticancer Res 25: 3003-3009.

Patel-Hett S, D'Amore PA (2011) Signal transduction in vasculogenesis and developmental angiogenesis. Int $\mathrm{J}$ Dev Biol 55:353-363.

Prahlad V, Yoon M, Moir RD, Vale RD, Goldman RD (1998) Rapid movements of vimentin on microtubule tracks: kinesin-dependent assembly of intermediate filament networks. J Cell Biol 143:159-170.
Qin Z, Kreplak L, Buehler MJ (2009) Nanomechanical properties of vimentin intermediate filament dimers. Nanotechnology 20:425101.

Semenza GL, Prabhakar NR (2007) HIF-1-dependent respiratory, cardiovascular, and redox responses to chronic intermittent hypoxia. Antioxid Redox Signal 9: 1391-1396.

Styers ML, Kowalczyk AP, Faundez V (2005) Intermediate filaments and vesicular membrane traffic: the odd couple's first dance? Traffic 6, 359-365.

Tomita S, Ueno M, Sakamoto M, Kitahama Y, Ueki M, Maekawa N, Sakamoto H, Gassmann M, Kageyama R, Ueda N, Gonzalez FJ, Takahama Y (2003) Defective brain development in mice lacking the Hif-1alpha gene in neural cells. Mol Cell Biol 23:6739-6749.

Tsuruta D, Jones JC (2003) The vimentin cytoskeleton regulates focal contact size and adhesion of endothelial cells subjected to shear stress. J Cell Sci 116:49774984. 